\title{
Differential radiologic characteristics of renal tumours on multiphasic computed tomography
}

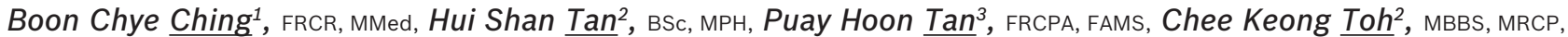
Ravindran Kanesvaran ${ }^{2}$, MBBS, MRCP, Quan Sing $\underline{N g}^{2}$, MD, MRCP, Min Han $\underline{T a n}^{2}$, FRCP, PhD

INTRODUCTION This study analysed the tumour attenuation characteristics of different subtypes of renal cell carcinomas (RCCs), including clear cell RCC (ccRCC), papillary RCC (pRCC), mixed RCC, chromophobe RCC (chRCC) and oncocytoma. METHODS We randomly selected 100 RCC cases that underwent nephrectomy between 2004 and 2012 from a collaborative database. Of these cases, 36 were excluded due to the absence of available imaging. The remaining 64 cases comprised 35 ccRCCs, 11 pRCCs, eight chRCCs, seven mixed RCCs and three oncocytomas. The cases were classified as computed tomography (CT) kidney, CT urogram (with plain, nephrographic and pyelographic phases) or CT abdomen (with portovenous and delayed phases). A circular region of interest $(\mathrm{ROI}) \geq 1 \mathrm{~cm}^{2}$ was drawn and the same standard ROI size was used for each phase at the same site; three different circular ROls were drawn per lesion per phase. Analysis of variance and $t$-test were used to examine differences in the radiological characteristics.

RESULTS There was no statistical difference in the attenuation and degree of enhancement between mixed RCCs and ccRCCs. The attenuation and degree of enhancement of the oncocytomas were significantly higher than those of the other RCC subtypes.

CONCLUSION While mixed RCCs did not have attenuation characteristics that differed significantly from those of ccRCCs, oncocytomas can be distinguished from cCRCCs, pRCCs, chRCCs and mixed RCCs by their high radiological density and enhancement. The ability to differentiate oncocytomas from these tumours potentially allows the preoperative selection of patients with small renal masses for conservative management.

Keywords: attenuation, clear cell renal cell carcinoma, enhancement, radiodensity, renal cell carcinoma

\section{INTRODUCTION}

Renal cell carcinoma (RCC) is the most common epithelial cancer in the adult kidney. It is the ninth most common cancer among adult men in Singapore, according to the 2010-2014 Singapore Cancer Registry report released in May 2015.(1) The incidence of RCC has been rising, with RCC accounting for $3.6 \%$ of all adult male malignancies in Singapore. ${ }^{(1)}$ Risk factors for RCC include male gender, age 50-80 years, obesity and an increased use of imaging techniques. ${ }^{(2-5)}$ Most of the renal tumours diagnosed on imaging are incidental, asymptomatic, small in size and in an early stage. ${ }^{(6)}$

The two most common types of RCC are clear cell RCC (cCRCC) and papillary RCC (pRCC), which constitute approximately $60 \%-65 \%$ and $13 \%-15 \%$, respectively, of all RCCs. ${ }^{(7)}$ The latter has a slightly better prognosis. ${ }^{(8,9)}$ Chromophobe RCC (chRCC), which accounts for about $5 \%$ of all RCCs, is known to have a very favourable clinical outcome, with a low risk of tumour progression, metastasis and mortality. ${ }^{(10)}$ Oncocytoma, a benign renal tumour that accounts for approximately $5 \%$ of all renal tumours, has an extremely favourable prognosis. ${ }^{(11)}$ Tumours with an admixture of morphological patterns (i.e. mixed RCCs), such as those with clear cell and papillary appearances, are generally less well described. Previous studies have focused on differentiating cCRCCs from pRCCs using multiphasic computed tomography $(\mathrm{CT})^{(12-14)}$ and there has been little emphasis on oncocytomas or chRCCs. To the best of our knowledge, the radiological characteristics of mixed RCCs have not been described. Thus, the aim of the present study was to retrospectively analyse the tumour attenuation characteristics of the different subtypes of RCCs, namely cCRCC, pRCC, mixed RCC, chRCC and oncocytoma.

\section{METHODS}

We randomly sampled 100 available RCC cases that underwent nephrectomy between 2004 and 2012 from a collaborative database. These included cases in which the RCC diagnosis was made between 2004 and 2012, cases that fell within the prespecified histological subtypes of cCRCC, pRCC, mixed RCC, chRCC and oncocytoma, and cases for which images were available from Singapore General Hospital, Singapore. Images from imaging performed prior to 2004 were not available, as they had not been transferred from a previous archival system. Therefore, images from only 64 of the 100 sampled cases were available for analysis. Permission from the Central Institutional Review Board was obtained for this study.

All multidetector CT was done using Philips Brilliance iCT (Philips Healthcare, Amsterdam, Netherlands), Siemens Somatom Definition, Siemens Sensation Cardiac (both Siemens Healthcare, Erlangen, Germany) or Toshiba Aquilion 64 (Toshiba Medical Systems, Zoetermeer, Netherlands). Imaging was performed according to a standardised protocol using $1.5 \mathrm{~mL} / \mathrm{kg}$ of Omnipaque 350 or Optiray 350. The contrast agent was

${ }^{1}$ Department of Diagnostic Radiology, Singapore General Hospital, ${ }^{2}$ Division of Medical Oncology, National Cancer Centre Singapore, ${ }^{3}$ Department of Pathology, Singapore General Hospital, Singapore

Correspondence: Dr Ching Boon Chye, Consultant, Department of Diagnostic Radiology, Singapore General Hospital, Outram Road, Singapore 169608. riqq@hotmail.com 
automatically injected at a flow rate of $2 \mathrm{~mL} / \mathrm{s}$ with the patient in a supine position, and each phase was performed during expiration.

As the cases involved different indications, some of them had images in three phases (plain, nephrographic and pyelographic), while others had images in two phases (portovenous and delayed). Among the 64 cases of RCC analysed, ten underwent CT abdomen (without plain scan), 31 underwent CT kidney and 23 underwent CT urogram. In cases where CT kidney was ordered, unenhanced imaging was performed before contrast administration; the nephrographic and pyelographic phases were then taken at 75 seconds and four minutes post-injection, respectively. Images during the corticomedullary phase are not routinely obtained in our standard CT kidney protocol, unless indicated (i.e. in situations where assessment of the vascular anatomy is necessary, such as when a partial nephrectomy or an intervention procedure has been planned). In cases where CT urogram was ordered, unenhanced imaging was performed before contrast administration; the nephrographic and pyelographic phases were then taken at 75 seconds and 7-10 minutes postinjection, respectively. Intravenous diuretics (10 mg frusemide) were administered by the radiologist prior to CT urogram. In cases where $\mathrm{CT}$ abdomen was ordered, portovenous imaging was performed at 75 seconds post-injection, and delayed imaging was performed at four minutes post-injection if an abnormal lesion was seen in the liver, kidney or spleen. The images were viewed using Microsoft Amalga imaging system version 5.1 (Microsoft, Redmond, WA, USA).

A dedicated radiologist, who was blinded to the histological subtype of the tumour, looked at the available images (plain, nephrographic and pyelographic phase images, or portovenous and delayed phase images). A circular region of interest (ROI) $\geq 1 \mathrm{~cm}^{2}$ was drawn in the most homogeneous and most enhancing area of the solid tumour lesion. The same standard ROI size (excluding necrotic or cystic area, normal parenchyma, bleed and calcifications) was used for each phase at the same site. Three different circular ROIs were drawn per lesion per phase. The mean attenuation values for each phase were quantified in Hounsfield units. The degree of enhancement was calculated using the attenuation of the phase (i.e. nephrographic or pyelographic) after contrast administration, minus the attenuation of the lesion without contrast (i.e. plain scan).

Descriptive statistics were used to summarise the patients' baseline demographic characteristics and tumour characteristics. One-way analysis of variance was used to compare the mean attenuation values of the different RCC subtypes. Two-sample independent $t$-test was used to compare the attenuation values between each of the RCC subtypes, as well as between malignant RCC and renal oncocytoma. All tests of statistical significance were two-sided, with the significance level set at 0.05. Data analysis was performed using STATA version 12.0 (STATA Corp, College Station, TX, USA).

\section{RESULTS}

A total of 64 patients were included in this study. Among these patients, $35(54.7 \%)$ had cCRCCs, 11 (17.2\%) had

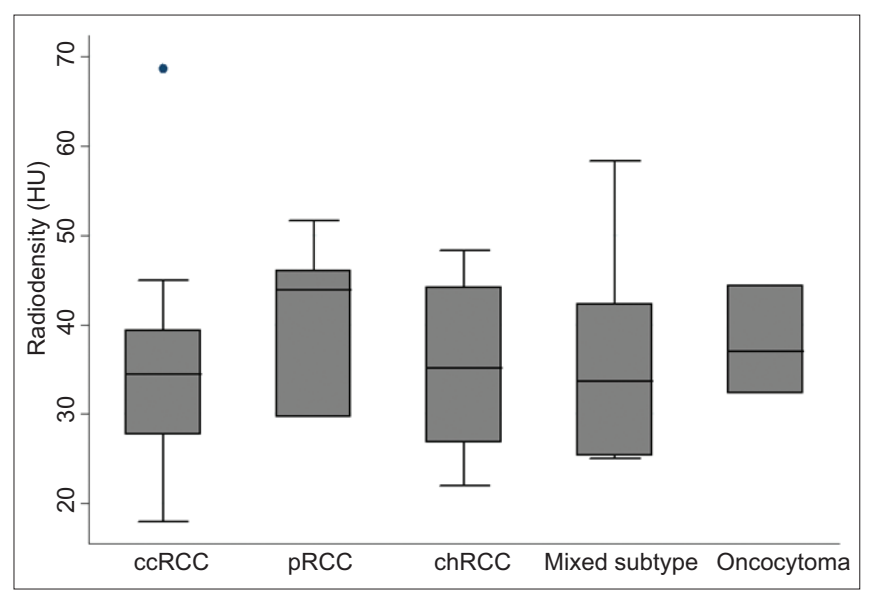

Fig. 1 Box plot shows the attenuation values of the different renal cell carcinoma subtypes in the plain radiologic phase. ccRCC: clear cell renal cell carcinoma; chRCC: chromophobe renal cell carcinoma; HU: Hounsfield units; pRCC: papillary renal cell carcinoma

pRCCs, $8(12.5 \%)$ had chRCCs, 7 (10.9\%) had mixed RCCs and $3(4.7 \%)$ had oncocytomas. The baseline characteristics of these 64 patients, including information on their RCCs, are shown in Table I. Notably, the majority of RCCs had a histology grade of 2 or 3 . Most of the RCCs were found to be in the upper pole, followed by the middle region. The majority of tumours had heterogeneous enhancement $(81.3 \%)$ and were solid in consistency (75.0\%). Most of the mixed RCCs were solid masses ( $\mathrm{n}=4,57.1 \%)$, while $1(14.3 \%)$ was a cystic mass with small solid components and 2 (28.6\%) were mixed solid-cystic masses. Among the 63 tumours for which information on bleed was available, only one, a ccRCC, had bleeding. Internal calcifications were observed in $22.2 \%$ of the 63 RCCs, septation was observed in $25.4 \%$, and local invasion was observed in $6.3 \%$ (three pRCCs and one mixed RCC).

The attenuation and enhancement values of the different subtypes of RCCs are shown in Table II. On unenhanced imaging, the attenuation values did not vary much among the subtypes ( $p>0.05$ ) (Fig. 1). On the nephrographic phase images, the attenuation values and degree of enhancement were consistently higher among the cCRCCs than the pRCCs (Figs. 2 \& 3); $t$-test showed that this difference was significant $(p<0.0001)$ (Table III). The differences in the attenuation values and degree of enhancement between the cCRCCs and mixed RCCs were not significant (Tables II \& III), while those between the cCRCCs and chRCCs were significant only in the nephrographic phase images (Figs. $2 \& 3$ ); $t$-test showed $p=0.0386$ for attenuation and $p=0.0475$ for enhancement (Table III). The attenuation value and degree of enhancement were consistently higher in the oncocytomas than in all the other RCC subtypes ( $t$-test $p=0.008$; Table III); this was seen in both the nephrographic and pyelographic phase images (Figs. 2-5).

\section{DISCUSSION}

Previous studies have demonstrated that multiphasic $\mathrm{CT}^{(12-14)}$ and magnetic resonance imaging(15) can be useful in differentiating cCRCCs from pRCCs. The results of the present study provided independent validation and showed that both attenuation 
Table I. Baseline characteristics of the patients $(n=64)$.

\begin{tabular}{|c|c|c|c|c|c|c|}
\hline \multirow[t]{2}{*}{ Variable } & \multicolumn{6}{|c|}{ No. (\%) } \\
\hline & $\begin{array}{c}\text { All } \\
(n=64)\end{array}$ & $\begin{array}{l}\text { ccRCC } \\
(n=35)\end{array}$ & $\begin{array}{c}\text { pRCC } \\
(n=11)\end{array}$ & $\begin{array}{l}\text { chRCC } \\
(n=8)\end{array}$ & $\begin{array}{c}\text { Mixed RCC } \\
(n=7)\end{array}$ & $\begin{array}{c}\text { Oncocytoma } \\
(n=3)\end{array}$ \\
\hline \multicolumn{7}{|l|}{ Gender } \\
\hline Male & $41(64.1)$ & $26(74.3)$ & $7(63.6)$ & $4(50.0)$ & $4(57.1)$ & $0(0)$ \\
\hline Female & $23(35.9)$ & $9(25.7)$ & $4(36.4)$ & $4(50.0)$ & $3(42.9)$ & $3(100.0)$ \\
\hline \multicolumn{7}{|l|}{ Ethnicity } \\
\hline Chinese & $53(82.8)$ & $30(85.7)$ & $9(81.8)$ & $6(75.0)$ & $6(85.7)$ & $2(66.7)$ \\
\hline Indian & $7(10.9)$ & $3(8.6)$ & $1(9.1)$ & $1(12.5)$ & $1(14.3)$ & 1 (33.3) \\
\hline Malay & $4(6.3)$ & $2(5.7)$ & $1(9.1)$ & $1(12.5)$ & $0(0)$ & $0(0)$ \\
\hline \multicolumn{7}{|l|}{ Tumour characteristic } \\
\hline \multicolumn{7}{|l|}{ Histology grade ${ }^{\ddagger}$} \\
\hline 1 & $1(1.6)$ & $1(2.9)$ & $0(0)$ & $0(0)$ & $0(0)$ & NA \\
\hline 2 & $32(52.5)$ & $24(68.6)$ & $4(36.4)$ & $2(25.0)$ & $2(28.6)$ & NA \\
\hline 3 & $21(34.4)$ & $9(25.7)$ & $5(45.5)$ & $3(37.5)$ & $4(57.1)$ & NA \\
\hline 4 & $5(8.2)$ & $0(0)$ & $2(18.2)$ & $2(25.0)$ & $1(14.3)$ & NA \\
\hline Unknown & $2(3.3)$ & $1(2.9)$ & $0(0)$ & $1(12.5)$ & $0(0)$ & NA \\
\hline \multicolumn{7}{|l|}{ Pole" } \\
\hline Upper & $21(36.8)$ & $8(27.6)$ & $6(60.0)$ & $3(37.5)$ & $1(14.3)$ & $3(100.0)$ \\
\hline Middle & $13(22.8)$ & $10(34.5)$ & $1(10.0)$ & $1(12.5)$ & $1(14.3)$ & $0(0)$ \\
\hline Lower & $9(15.8)$ & $6(20.7)$ & $1(10.0)$ & $1(12.5)$ & $1(14.3)$ & $0(0)$ \\
\hline Upper/middle & $4(7.0)$ & $2(6.9)$ & $0(0)$ & $0(0)$ & $2(28.6)$ & $0(0)$ \\
\hline Middle/lower & $7(12.3)$ & $3(10.3)$ & $1(10.0)$ & $2(25.0)$ & $1(14.3)$ & $0(0)$ \\
\hline All & $2(3.5)$ & $0(0)$ & $1(10.0)$ & $1(12.5)$ & $0(0)$ & $0(0)$ \\
\hline \multicolumn{7}{|l|}{ Homogeneity } \\
\hline Homogeneous & $12(18.8)$ & $3(8.6)$ & $4(36.4)$ & $2(25.0)$ & $1(14.3)$ & $2(66.7)$ \\
\hline Heterogeneous & $52(81.3)$ & $32(91.4)$ & $7(63.6)$ & $6(75.0)$ & $6(85.7)$ & $1(33.3)$ \\
\hline \multicolumn{7}{|l|}{ Solid/cystic } \\
\hline Solid & $48(75.0)$ & $27(77.1)$ & $7(63.6)$ & $7(87.5)$ & $4(57.1)$ & $3(100.0)$ \\
\hline Cystic & $4(6.3)$ & $1(2.9)$ & $2(18.2)$ & $0(0)$ & $1(14.3)$ & $0(0)$ \\
\hline Mixed & $12(18.8)$ & $7(20.0)$ & $2(18.2)$ & $1(12.5)$ & $2(28.6)$ & $0(0)$ \\
\hline \multicolumn{7}{|l|}{ Bleed $^{\S}$} \\
\hline No & $62(98.4)$ & $34(97.1)$ & $11(100.0)$ & $7(100.0)$ & $7(100.0)$ & $3(100.0)$ \\
\hline Yes & $1(1.6)$ & $1(2.9)$ & $0(0)$ & $0(0)$ & $0(0)$ & $0(0)$ \\
\hline \multicolumn{7}{|l|}{ Calcifications and $\mathrm{fat}^{\S}$} \\
\hline No & $49(77.8)$ & $27(77.1)$ & $10(90.9)$ & $3(42.9)$ & $6(85.7)$ & $3(100.0)$ \\
\hline Yes & $14(22.2)$ & 8 (22.9) & $1(9.1)$ & $4(57.1)$ & $1(14.3)$ & $0(0)$ \\
\hline \multicolumn{7}{|l|}{ Septation ${ }^{\S}$} \\
\hline No & $47(74.6)$ & $32(91.4)$ & $6(54.5)$ & $2(28.6)$ & $4(57.1)$ & $3(100.0)$ \\
\hline Yes & $16(25.4)$ & $3(8.6)$ & $5(45.5)$ & $5(71.4)$ & $3(42.9)$ & $0(0)$ \\
\hline \multicolumn{7}{|l|}{ Local invasion $\S$} \\
\hline No & $59(93.7)$ & $35(100.0)$ & $8(72.7)$ & $7(100.0)$ & $6(85.7)$ & $3(100.0)$ \\
\hline Yes & $4(6.3)$ & $0(0)$ & $3(27.3)$ & $0(0)$ & $1(14.3)$ & $0(0)$ \\
\hline \multicolumn{7}{|l|}{ Metastasis $^{\S}$} \\
\hline No & 59 (93.7) & $35(100.0)$ & $9(81.8)$ & $6(85.7)$ & $7(100.0)$ & $2(66.7)$ \\
\hline Yes & $4(6.3)$ & $0(0)$ & $2(18.2)$ & $1(14.3)$ & $0(0)$ & 1 (33.3) \\
\hline
\end{tabular}

*Data presented as median (range). +Data presented as mean \pm standard deviation. $¥$ Total for 'all patients' does not equal 64 because histology grade is not applicable to oncocytomas. ๆTotal for 'all patients', 'ccRCC patients' and 'pRCC patients' were not 64,35 and 11, respectively, due to missing data. §Total for 'all patients' and 'chRCC patients' were not 64 and 8, respectively, due to missing data. ccRCC: clear cell renal cell carcinoma; chRCC: chromophobe renal cell carcinoma; NA: not applicable; pRCC: papillary renal cell carcinoma 
Table II. Analysis of variance of the radiodensity profiles of the renal cell carcinoma subtypes.

\begin{tabular}{lcccccc}
\hline Variable & \multicolumn{4}{c}{ Radiodensity (HU) (mean \pm standard deviation) } \\
\cline { 2 - 5 } & ccRCC & pRCC & chRCC & Mixed RCC & Oncocytoma \\
\hline Plain $(n=56)$ & $34.06 \pm 9.58$ & $40.78 \pm 9.14$ & $35.33 \pm 9.78$ & $36.05 \pm 12.06$ & $37.89 \pm 6.05$ & 0.6229 \\
Nephrographic $(n=64)$ & $95.17 \pm 27.59$ & $66.58 \pm 12.21$ & $73.13 \pm 19.03$ & $87.14 \pm 23.39$ & $128.78 \pm 24.09$ & 0.0005 \\
Pyelographic $(n=63)$ & $69.36 \pm 13.84$ & $60.67 \pm 10.23$ & $62.14 \pm 9.50$ & $69.81 \pm 9.86$ & $93.00 \pm 13.69$ & 0.0032 \\
Nephrographic enhancement $(n=56)$ & $58.58 \pm 26.38$ & $32.89 \pm 12.00$ & $37.79 \pm 22.33$ & $51.10 \pm 26.16$ & $90.89 \pm 19.39$ & 0.0068 \\
Pyelographic enhancement $(n=55)$ & $36.00 \pm 15.99$ & $24.61 \pm 13.42$ & $24.90 \pm 14.10$ & $33.76 \pm 12.25$ & $55.11 \pm 14.30$ & 0.0337 \\
\hline
\end{tabular}

ccRCC: clear cell renal cell carcinoma; chRCC: chromophobe renal cell carcinoma; HU: Hounsfield units; mixed RCC: mixed renal cell carcinoma; pRCC: papillary renal cell carcinoma

Table III. Two-sample independent $t$-test of the radiodensity profiles of the renal cell carcinoma subtypes.

\begin{tabular}{lccccccc}
\hline Variable & \multicolumn{7}{c}{ p-value } \\
\cline { 2 - 8 } & $\begin{array}{c}\text { ccRCC vs. } \\
\text { pRCC }\end{array}$ & $\begin{array}{c}\text { ccRCC vs. } \\
\text { chRCC }\end{array}$ & $\begin{array}{c}\text { pRCC vs. } \\
\text { chRCC }\end{array}$ & $\begin{array}{c}\text { ccRCC vs. } \\
\text { mixed RCC }\end{array}$ & $\begin{array}{c}\text { pRCC vs. } \\
\text { mixed RCC }\end{array}$ & $\begin{array}{c}\text { chRCC vs. } \\
\text { oncocytoma }\end{array}$ & $\begin{array}{c}\text { Malignant RCCs* } \\
\text { vs. oncocytoma }\end{array}$ \\
\hline Nephrographic & 0.0001 & 0.0386 & 0.3724 & 0.4768 & 0.0255 & 0.0029 & 0.0080 \\
Pyelographic & 0.0615 & 0.1968 & 0.7633 & 0.9357 & 0.0794 & 0.0031 & 0.0010 \\
Nephrographic enhancement & 0.0260 & 0.0475 & 0.6366 & 0.4999 & 0.1465 & 0.0056 & 0.0128 \\
Pyelographic enhancement & 0.1107 & 0.0986 & 0.9702 & 0.7303 & 0.2249 & 0.0148 & 0.0182 \\
\hline
\end{tabular}

*Malignant RCCs include ccRCCs, pRCCs, chRCCs and mixed RCCs. ccRCC: clear cell renal cell carcinoma; chRCC: chromophobe renal cell carcinoma; mixed RCC: mixed renal cell carcinoma; pRCC: papillary renal cell carcinoma

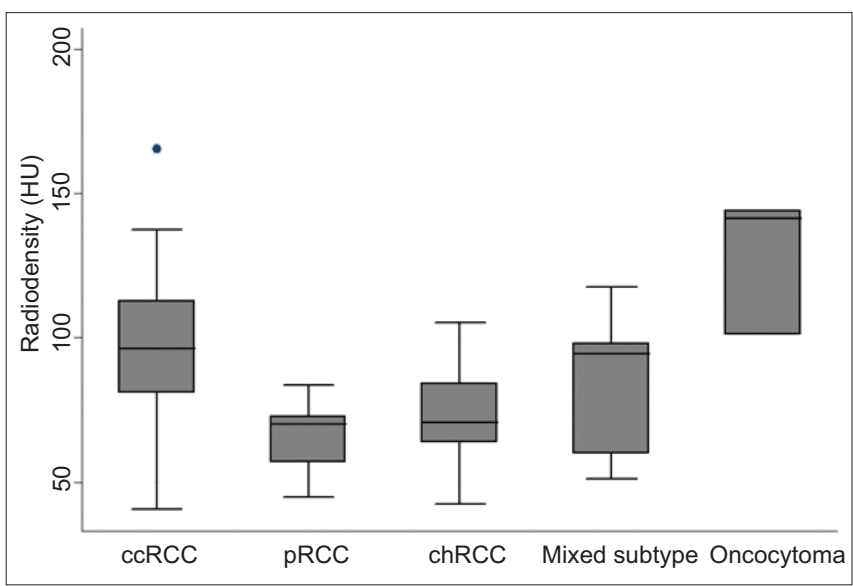

Fig. 2 Box plot shows the attenuation values of the different renal cell carcinoma subtypes in the nephrographic phase. ccRCC: clear cell renal cell carcinoma; chRCC: chromophobe renal cell carcinoma; HU: Hounsfield units; pRCC: papillary renal cell carcinoma

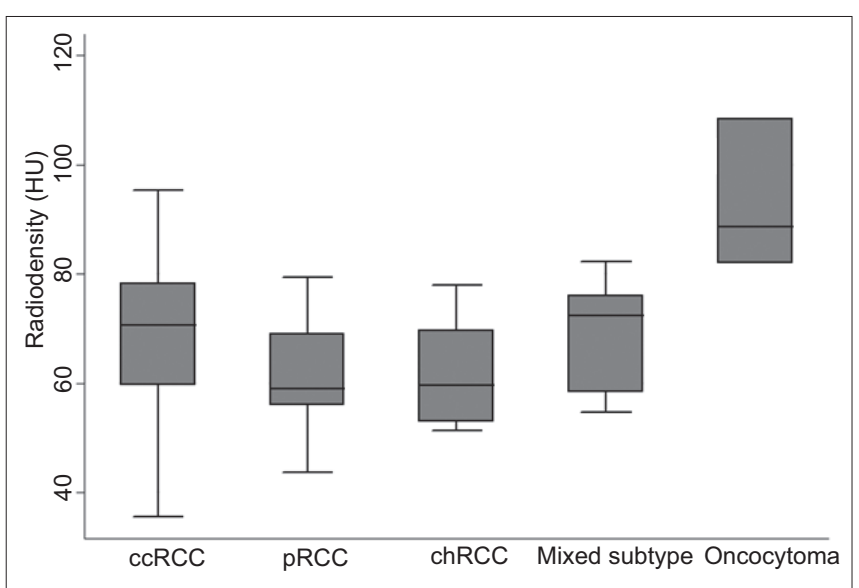

Fig. 4 Box plot shows the attenuation values of the different renal cell carcinoma subtypes in the pyelographic phase. ccRCC: clear cell renal cell carcinoma; chRCC: chromophobe renal cell carcinoma; HU: Hounsfield units; pRCC: papillary renal cell carcinoma

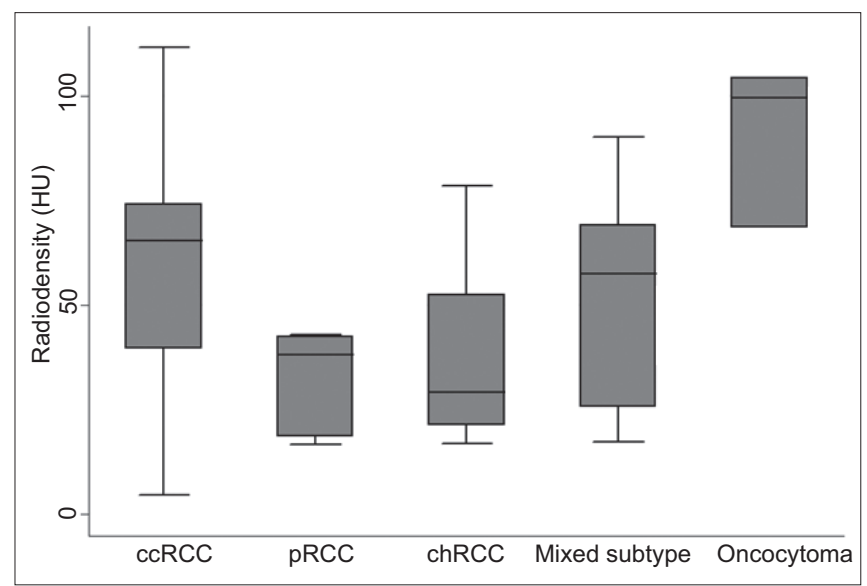

Fig. 3 Box plot shows the degree of enhancement of the different renal cell carcinoma subtypes in the nephrographic phase. ccRCC: clear cell renal cell carcinoma; chRCC: chromophobe renal cell carcinoma; HU: Hounsfield units; pRCC: papillary renal cell carcinoma

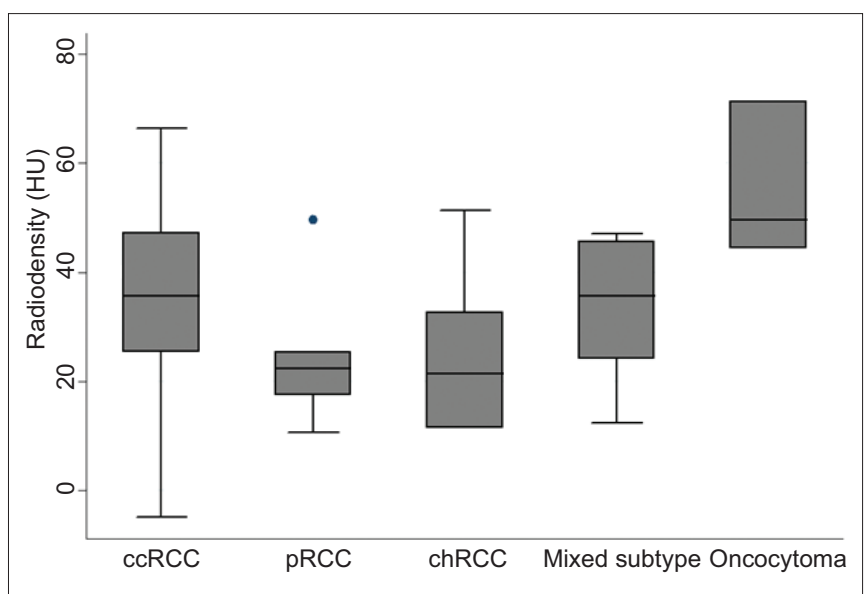

Fig. 5 Box plot shows the degree of the enhancement of the different renal cell carcinoma subtypes in the pyelographic phase. ccRCC: clear cell renal cell carcinoma; chRCC: chromophobe renal cell carcinoma; HU: Hounsfield units; pRCC: papillary renal cell carcinoma 
and degree of enhancement in the nephrographic phase are significantly lower for pRCCs than cCRCCs. This is useful because cCRCCs are known to have a poorer prognosis than pRCCs. Although the reason for the difference in attenuation and degree of enhancement is unclear, it is likely to be related to differences in tumour vascularity. The presence of somatic von Hippel-Lindau alterations in the tumours, which is a distinguishing feature of most ccRCCs, results in the activation of the hypoxia-inducible factor pathways, leading to increased vascularity.

Preoperative radiology can potentially be used to identify patients with benign renal masses that may be treated conservatively (i.e. without surgery). In the present study, all the oncocytomas identified showed significantly higher attenuation and degree of enhancement relative to the other malignant tumours (i.e. cCRCC, pRCC, mixed RCC and chRCC), in both the nephrographic and pyelographic phases. This finding is concordant with two other independent reports. ${ }^{(16,17)}$ The median size of the oncocytomas in our study was $3.5 \mathrm{~cm}$, which is, by definition, a small renal mass (SRM) $(<4 \mathrm{~cm})$. The argument that SRMs should be treated with nephron-sparing surgery independent of their histological nature ${ }^{(18)}$ may be re-examined in the light of such findings. A prospective study on the preoperative classification of SRMs, with the aim of identifying those that can be conservatively managed, is warranted.

Interestingly, we found divergent radiological results for oncocytomas and chRCCs in our study, although these two entities are known to have many similarities in terms of genetics and morphology. A literature review showed that chRCCs have enhancement characteristics that fall between those of ccRCCs and pRCCs; ${ }^{(19)}$ this is concordant with the results of our study (Table III).

To the best of our knowledge, there has been no published study investigating the radiological characteristics of mixed RCCs using multiphasic CT. In the present study, there were seven patients with mixed RCCs and their median age of diagnosis was 47 years, which is lower than the average age of RCC presentation (Table I). Our data also showed that there was no statistically significant difference between the attenuation of mixed RCCs and that of cCRCCs in the plain, nephrographic and pyelographic phases that would enable effective differentiation between the two subtypes. However, the degree of enhancement of mixed RCCs was similar to those of cCRCCs and pRCCs in both the nephrographic and pyelographic phases (Table III).

The present study was not without limitations. First, this was a retrospective study; a prospective study with larger sample sizes may yield more information. The heterogeneity of the imaging techniques used and the small sample sizes of the RCC subtypes, particularly mixed RCCs, were also limitations. Nonetheless, we opine that the RCC cases included were representative of the spectrum of RCCs, as they were randomly selected from a large clinical database. Finally, whole-lesion evaluation, instead of ROI-based evaluation, may potentially yield different results.
In conclusion, the present study showed that the different histological subtypes of RCCs have varying characteristics on preoperative CT imaging. We found no statistically significant difference between the attenuation of mixed RCCs and that of ccRCCs in the plain, nephrographic and pyelographic phases, and thus it was not possible to effectively differentiate between the two subtypes. However, oncocytomas can be distinguished from cCRCCs, pRCCs, mixed RCCs and chRCCs by their high degree of enhancement. The ability to distinguish oncocytomas from these other tumours potentially allows for the preoperative selection of patients with SRMs for conservative management.

\section{REFERENCES}

1. Singapore Cancer Registry Interim Annual Report. Trends in Cancer Incidence in Singapore 2010-2014. Available at: https://www.nrdo.gov.sg/docs/ librariesprovider3/default-document-library/cancer-trends-2010-2014_interimannual-report_final-(public).pdf?sfvrsn=0\&AspxAutoDetectCookieSupport=1 . Accessed January 7, 2016

2. Taccoen X, Valeri A, Descrotes JL, et al; Oncology Committee of the Association Française d'Urologie. Renal cell carcinoma in adults 40 years old or less: young age is an independent prognostic factor for cancer-specific survival. Eur Urol 2007; 51:980-7.

3. Verhoest $G$, Veillard D, Guillé F, et al. Relationship between age at diagnosis and clinicopathologic features of renal cell carcinoma. Eur Urol 2007; 51:1298-304.

4. Leslie JA, Prihoda T, Thompson IM. Serendipitous renal cell carcinoma in the post-CT era: continued evidence in improved outcomes. Urol Oncol 2003; 21:39-44.

5. Hu J, Mao Y, White K; Canadian Cancer Registries Epidemiology Research Group. Overweight and obesity in adults and risk of renal cell carcinoma in Canada. Soz Praventivmed 2003; 48:178-85.

6. Hock LM, Lynch J, Balaji KC. Increasing incidence of all stages of kidney cancer in the last 2 decades in the United States: an analysis of surveillance, epidemiology and end results program data. J Urol 2002; 167:57-60.

7. Reuter VE. The pathology of renal epithelial neoplasms. Semin Oncol 2006; 33:534-43.

8. Mydlo JH, Bard RH. Analysis of papillary renal adenocarcinoma. Urology 1987; 30:529-34.

9. Störkel S, Thoenes W, Jacobi GH, Lippold R. Prognostic parameters in renal cell carcinoma--a new approach. Eur Urol 1989; 16:416-22.

10. Volpe A, Novara G, Antonelli A, et al; Surveillance and Treatment Update on Renal Neoplasms (SATURN) Project; Leading Urological No-Profit Foundation for Advanced Research (LUNA) Foundation. Chromophobes renal cell carcinoma (RCC): oncological outcomes and prognostic factors in a large multicentre series. BJU Int 2012; 110:76-83.

11. Amin MB, Amin MB, Tamboli P, et al. Prognostic impact of histologic subtyping of adult renal epithelial neoplasms: an experience of 405 cases. Am J Surg Pathol 2002; 26:281-91.

12. Chen $F$, Huhdanpaa $H$, Desai $B$, et al. Whole lesion quantitative $C T$ evaluation of renal cell carcinoma: differentiation of clear cell from papillary renal cell carcinoma. Springerplus 2015; 4:66.

13. Bata P, Gyebnar J, Tarnoki DL, et al. Clear cell renal cell carcinoma and papillary renal cell carcinoma: differentiation of distinct histological types with multiphase CT. Diagn Interv Radiol 2013; 19:387-92.

14. Kim JK, Kim TK, Ahn HJ, et al. Differentiation of subtypes of renal cell carcinoma on helical CT scans. AJR Am J Roentgenol 2002; 178:1499-506.

15. Chandarana H, Rosenkrantz AB, Mussi TC, et al. Histogram analysis of wholelesion enhancement in differentiating clear cell from papillary subtype of renal cell carcinoma. Radiology 2012; 265:790-8.

16. Bird VG, Kanagarajah P, Murillo G, et al. Differentiation of oncocytoma and renal cell carcinoma in small renal masses $(<4 \mathrm{~cm})$ : the role of 4 -phase computerized tomography. World J Urol 2011; 29:787-92.

17. Gakis G, Kramer $U$, Schilling D, et al. Small cell oncocytomas: differentiation with multiphase CT. Eur J Radiol 2011; 80:274-8.

18. Pusiol T, Zorzi MG, Morichetti D, Piscioli I, Scialpi M. Uselessness of radiological differentiation of oncocytoma and renal cell carcinoma in management of small renal masses. World J Urol 2013; 31:1013-4.

19. Raman SP, Johnson PT, Allaf ME, Netto G, Fishman EK. Chromophobe renal cell carcinoma: multiphase MDCT enhancement patterns and morphologic features. AJR Am J Roentgenol 2013; 201:1268-76. 